\title{
Effect of hydrothermal treatment on the carbon structure of Inner Mongolia lignite
}

\author{
Peng Liu ${ }^{1} \cdot$ Dexiang Zhang ${ }^{2}$
}

Received: 5 December 2019/Revised: 17 July 2020/Accepted: 29 July 2020/Published online: 11 August 2020

(C) The Author(s) 2020

\begin{abstract}
Understanding the structural properties of lignite during hydrothermal treatment would aid in predicting the subsequent behavior of coal during the pyrolysis, liquefaction, and gasification processes. Here, hydrothermal treatment of Inner Mongolia lignite (IM) was carried out in a lab autoclave. The distribution of carbon in the lignite was monitored via solid ${ }^{13} \mathrm{C}$ nuclear magnetic resonance spectroscopy, and the functional groups of oxygen in lignite were determined by Fourier transform infrared spectroscopy. The curve-fitting method was used to calculate the content of the functional groups quantitatively. The results show that hydrothermal treatment is an effective method for upgrading the lignite. The side chains of the aromatic ring in lignite are altered, while the main macromolecular structure remains nearly the same. The hydrothermal treatment of IM could be divided into three temperature-dependent stages. The first stage $(<493 \mathrm{~K})$ is the decomposition reaction of oxygen functional groups, where the $\mathrm{O} / \mathrm{C}$ ratio decreases from 0.203 in raw IM to 0.185 for the IM treated at $493 \mathrm{~K}$. In the second stage (493-533 K), hydrolysis of functional groups and hydrogen transfer between water and lignite occur. Here, the ratio of methylene to methyl increases from 0.871 in IM-493 to 1.241 for IM-533, and the content of quinone generates from the condensation of free phenol increased. The third stage ( $>533 \mathrm{~K})$ involves breakage of the covalent bond, and the content of $\mathrm{CH}_{4}$ and $\mathrm{CO}$ in the emission gas clearly increase.
\end{abstract}

Keywords Lignite $\cdot$ Hydrothermal treatment $\cdot$ Carbon structure $\cdot$ Solid ${ }^{13} \mathrm{C}$ nuclear magnetic resonance

\section{Introduction}

Lignite is an abundant fossil fuel resource and will continue to be an important energy source in the foreseeable future. Because of its high moisture content $(25 \mathrm{wt} \%-$ $60 \mathrm{wt} \%)$, the drying/dewatering is an integral step for

Peng Liu

liupeng@cczu.edu.cn

$\triangle$ Dexiang Zhang

zdx@ecust.edu.cn

$1 \quad$ National-Local Joint Engineering Research Center of Biomass Refining and High-Quality Utilization, Institute of Urban and Rural Mining, Changzhou University, Changzhou 213164, Jiangsu, China

2 Department of Chemical Engineering for Energy Resources, East China University of Science and Technology, Shanghai 200237, China lignite applications that require high efficiency. Hydrothermal treatment (Butler et al. 2007; Sakaguchi et al. 2008; Katalambula and Gupta 2009; Ullah et al. 2018), a non-evaporative technique, is considered an effective method for dewatering and upgrading lignite. The process enables an improvement in the slurry properties of coal (Yu et al. 2012; Fu and Wang 2014; Zhang et al. 2018) and can reduce the viscosity of the coal-water slurry. Moreover, hydrothermal treatment not only promotes the hydro-liquefaction activity during coal liquefaction ( $\mathrm{Li}$ et al. 2020) but also increases the coal concentration of the coal-solvent slurry (Inoue et al. 2012a, b), which is because of the lower porosity for the treated coal. Furthermore, hydrothermally treated lignite has a greater calorific value (Yu et al. 2014; Ullah et al. 2018) compared with raw lignite. Furthermore, contaminant elements in lignite, such as sulfur, nitrogen, and chlorine (Wang et al. 2016a, b; Zhao et al. 2020), can be fixed during hydrotreatment. 
The improvement of low-grade coal via hydrothermal treatment could benefit from a better understanding of the evolution of the structural properties of lignite during hydrothermal treatment. This would aid in predicting the behavior of coal subsequently during the pyrolysis, liquefaction, and gasification processes (Sun et al. 2004; Safarova et al. 2005 Wang et al. 2013a, b). Intensive research on the structure of coal has been undertaken using X-ray diffraction (XRD) (Sonibare et al. 2010; Wu et al. 2013; Yan et al. 2020), Fourier transform infrared spectroscopy (FTIR) (Ibarra et al. 1996; Wang et al. 2013a, b; $\mathrm{Wu}$ et al. 2013, 2014; Jiang et al. 2019), and Raman spectroscopy (Jiang et al. 2019; Liu et al. 2014). XRD spectroscopy is commonly used to study the crystal structure of carbonaceous materials. However, exploring the non-crystalline part of coal is difficult. Raman spectroscopy is a major technique used to evaluate the degree of ordering and crystallinity in carbonaceous materials. FTIR is very useful in probing the functional groups in coal and thus widely used for studying the chemical structure of coal. Combined with curve-fitting analysis (Ibarra et al. 1996; Wang et al. 2011, 2013a; Wu et al. 2013; Jiang et al. 2019), these methods can provide additional insight into the structure of coal and their structural parameters can be quantitatively analyzed. To better understand the carbon skeleton structure of coal, solid ${ }^{13} \mathrm{C}$ nuclear magnetic resonance $\left({ }^{13} \mathrm{C}-\mathrm{NMR}\right.$ ) spectroscopy (Wei et al. 2005; Erdenetsogt et al. 2010; Xiang et al. 2013; Yan et al. 2014) has been used to determine the chemical structure, which could be used to quantitatively characterize different existing types of carbon in coal.

The raw and hydrothermally-treated Inner Mongolia lignite (IM) structures were compared via their ${ }^{13} \mathrm{C}-\mathrm{NMR}$ spectra (Zhang et al. 2016). Hydrothermal treatment can break the cross-linked structure in lignite (Liu et al.
2016, 2017; Ge et al. 2018) to change the conversion pathway during pyrolysis. The water in the reaction can participate in one or more roles with the presence of oxygen functional groups (Siskina and Katritzky 2000; Feng et al. 2008) at the treatment temperature. The hydrogen from water was determined to be transferred to IM via analysis of pyrolysis tar using the isotopic tracer method (Wang et al. 2016a). As discussed above, previous studies focused on the correlation of the hydrothermal treatment of lignite with the pyrolysis product, while the structural evolution of lignite during hydrothermal treatment has largely been ignored. To the best of our knowledge, an indepth investigation of the structural evolution of lignite during hydrothermal treatment has yet to be carried out.

In this work, the structural evolution of IM during hydrothermal treatment was studied. The curve-fitting method was used to quantify the accurate chemical shift values of different structural carbons via ${ }^{13} \mathrm{C}$-NMR spectroscopy and the wavenumbers of the oxygen functional groups in lignite were determined using FTIR spectroscopy. Finally, changes in the lignite structure during hydrothermal treatment were determined.

\section{Experimental}

\subsection{Materials}

Inner Mongolia lignite (IM) from the Inner Mongolia province, China was ground to $<0.2 \mathrm{~mm}$ and stored under a cryogenic environment. The proximate and ultimate analyses of the lignite are shown in Table 1 . The raw lignite was dried under vacuum at $323 \mathrm{~K}$ for $8 \mathrm{~h}$ before characterization.

Table 1 Proximate and ultimate analyses of lignites

\begin{tabular}{|c|c|c|c|c|c|c|c|c|c|}
\hline \multirow[t]{2}{*}{ Sample } & \multirow[t]{2}{*}{ Yield (wt\%) } & \multicolumn{3}{|c|}{ Proximate analyses (wt\%) } & \multicolumn{5}{|c|}{ Ultimate analyses (wt\%) (daf) } \\
\hline & & $\mathrm{Ash}^{\mathrm{a}}$ & Volatile matter $^{\mathrm{b}}$ & Fixed carbon ${ }^{b}$ & $\mathrm{C}$ & $\mathrm{H}$ & $\mathrm{N}$ & $\mathrm{S}$ & $\mathrm{O}^{\mathrm{d}}$ \\
\hline $\mathrm{IM}$ & - & 14.41 & 46.48 & 53.52 & 72.99 & 4.65 & 1.16 & 1.40 & 19.80 \\
\hline IM- $473^{\mathrm{c}}$ & 93.35 & 14.38 & 46.94 & 53.06 & 73.62 & 5.53 & 1.20 & 1.63 & 18.02 \\
\hline IM-493 & 92.91 & 14.00 & 45.70 & 54.30 & 73.55 & 5.64 & 1.18 & 1.48 & 18.15 \\
\hline IM-513 & 90.56 & 14.22 & 43.01 & 56.99 & 74.27 & 5.72 & 1.22 & 1.42 & 17.37 \\
\hline IM-533 & 88.57 & 14.39 & 42.24 & 57.76 & 75.77 & 5.56 & 1.29 & 1.39 & 15.99 \\
\hline IM-573 & 84.55 & 14.79 & 39.84 & 60.16 & 78.16 & 5.40 & 1.30 & 1.36 & 13.78 \\
\hline
\end{tabular}

${ }^{\mathrm{a}}$ Dry basis

${ }^{\mathrm{b}}$ Dry ash-free basis

c "IM-473" indicates the IM was treated at $473 \mathrm{~K}$ for $30 \mathrm{~min}$; d-by difference 


\subsection{Methods}

\subsubsection{Hydrothermal treatment}

Hydrothermal treatment of lignite was carried out in a $500 \mathrm{~mL}$ autoclave. The water content of raw lignite is about $25 \%-60 \%$; for the experiments a value of about $40 \%$ was used and the original lignite state was simulated in the laboratory. For this, $80 \mathrm{~g}$ lignite and $48 \mathrm{~mL}$ deionized water were placed in the reactor and heated at a rate of $4 \mathrm{~K} /$ min to a certain temperature $(473,493,513,533,573 \mathrm{~K})$; then, stirred using a stirrer and maintained for $30 \mathrm{~min}$ under saturated vapor pressure. The treated lignite was then cooled to room temperature and removed from the reactor. The products were filtered to remove excess water, and then dried under vacuum at $323 \mathrm{~K}$ for $8 \mathrm{~h}$. The lignite hydrothermally treated at different temperatures is referred to as IM-473, IM-493, IM-513, IM-533, and IM-573.

The gas composition was analyzed via gas chromatography (GC) with a GC 126 instrument (INESA instrument, China), equipped with two detectors, i.e., a thermal conductivity detector (TCD) and a flame ionization detector (FID). The gas sampling bags were put under vacuum and purged several times before the experiments.

\subsubsection{Analysis of the raw and treated lignite}

\section{(1) Proximate and ultimate analyses}

The proximate analyses of the lignites were carried out using standard methods (ISO1171and ISO562). The elements $\mathrm{C}, \mathrm{H}, \mathrm{N}$, and $\mathrm{S}$ were analyzed using an elemental analyzer (Elementar Vario Micro Cube, Germany), and the percentage of oxygen was calculated using the difference.

$$
{ }^{13} \mathrm{C}-\mathrm{NMR}
$$

The carbon structure was determined via solid ${ }^{13} \mathrm{C}-\mathrm{NMR}$ using a Bruker Avance 500 NMR spectrometer (Germany) at a frequency of $125.77 \mathrm{MHz}$ for carbon and a frequency of $500.12 \mathrm{MHz}$ for the proton. Dry and powdered coals were packed into a $4 \mathrm{~mm}$ rotor. The solid ${ }^{13} \mathrm{C}$ NMR spectra were obtained at a spinning speed of $5.7 \mathrm{kHz}$ using a solid cross polarization/magic angle spinning (CP/MAS) probe and the total suppression of sidebands sequence (TOSS). The measurement conditions were as follows: the contact time was $1 \mathrm{~ms}$, with a recycle delay of $3 \mathrm{~s}$ and a scan number $>2000$. The corresponding chemical shifts for different carbon types have been investigated in numerous studies (Xiang et al. 2013; Yan et al. 2014; Erdenetsogt et al. 2010). Using data from other studies along with the ${ }^{13} \mathrm{C}$-NMR spectra of the raw and treated IM, the chemical shifts for different types of carbon were determined in our previously reported study (Liu et al. 2016). The

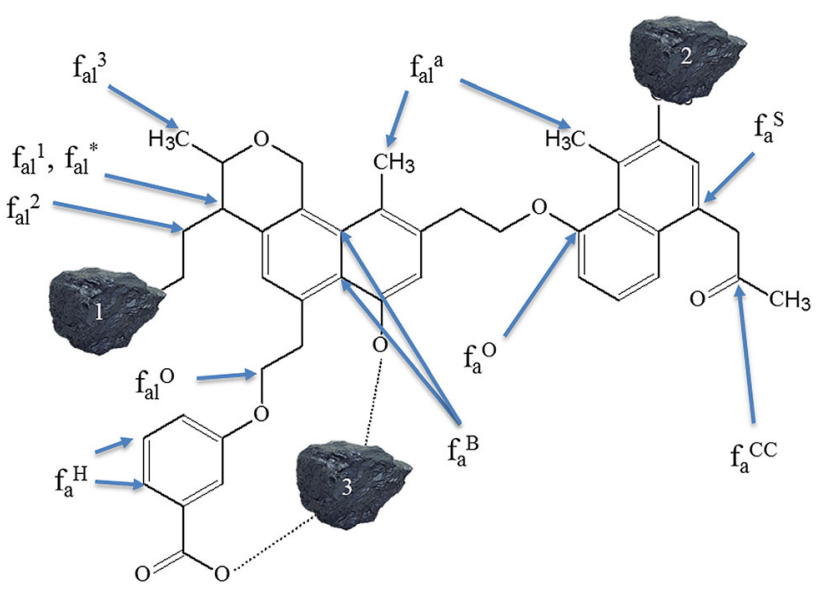

Fig. 1 Character of the carbon located in lignite

characteristics of the carbons located in lignite are shown in Fig. 1.

\section{(3) FTIR analyses}

The oxygen functional groups were analyzed via FTIR spectroscopy. Quantitative FTIR transmission spectra of the lignites were obtained with a Nicolet 6700 Fourier Transform infrared spectrometer (USA) using finely ground samples pressed in $\mathrm{KBr}$ pellets. A mixture of lignite and $\mathrm{KBr}$ (ratio of 1:100) was ground together and pressed into a pellet and then dried in a vacuum oven at $323 \mathrm{~K}$ for $24 \mathrm{~h}$. The spectra were recorded with various indexes between 4000 and $400 \mathrm{~cm}^{-1}$ by co-adding 32 scans at a resolution of $4 \mathrm{~cm}^{-1}$. The bands of the corresponding oxygen functional groups (region of $1000-1800 \mathrm{~cm}^{-1}$ ) for the FTIR spectra of the raw and treated IM were determined based on our previously reported study (Liu et al. 2016).

\section{(4) Curve-fitting method}

A range of functional groups in lignite clusters were marked by peak clusters in the spectra, rather than distinct sharp peaks with specific positions. To interpret the data, the peak separation and quantitative calculations were performed using a curve-fitting program in the Origin 8.0 software. The positions and number of bands were initially established from the second derivative of the spectrum, and a coefficient of determination $\left(R^{2}\right)$ of 0.998 for the desired fit of the experimental spectrum was obtained. The number of peaks in a given region was determined, and the frequency and intensity of each peak were estimated. Subsequently, each simulated peak was integrated to obtain the peak area, and the corresponding fraction relative to the total carbon integration of the spectrum was calculated to obtain the relative content of each unit. 


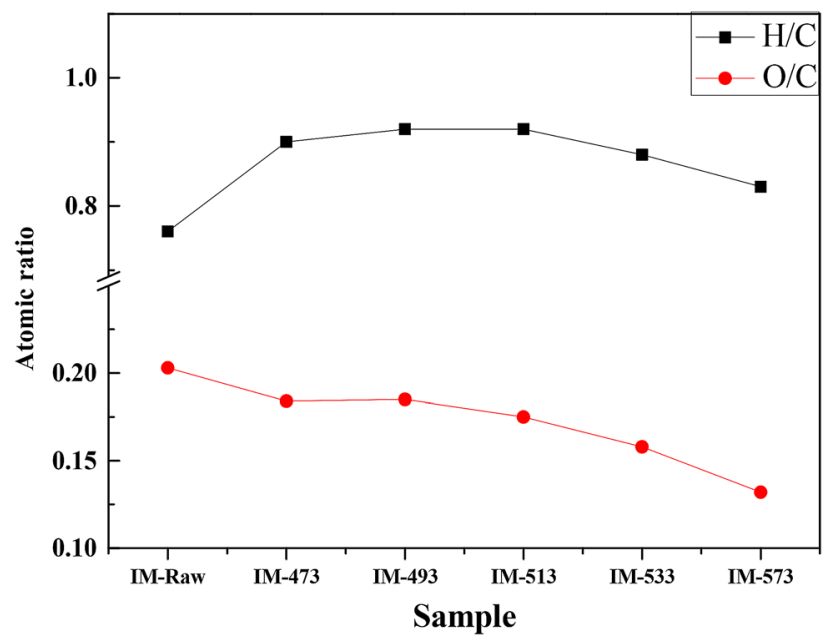

Fig. 2 Variation of $\mathrm{H} / \mathrm{C}$ and $\mathrm{O} / \mathrm{C}$ during hydrothermal treatment

\section{Results and discussion}

\subsection{Effect of hydrothermal treatment on preliminary evaluation of lignite composition}

The proximate and ultimate analyses of raw and treated IM are shown in Table 1.

The data in Table 1 indicates that the fixed carbon content of treated IM increased and the oxygen contents decreased with increasing temperature, especially above a temperature of $493 \mathrm{~K}$. The carbon contents of IM-533 and IM-573 were close to those of bituminous coal (Zhang 2014). The changes in the elemental composition led to an increase in the calorific value of treated IM. This indicated that the treated IM could be a better solid fuel than raw IM. The variation of $\mathrm{H} / \mathrm{C}$ and $\mathrm{O} / \mathrm{C}$ during hydrothermal treatment is shown in Fig. 2.

The $\mathrm{O} / \mathrm{C}$ ratio decreased from 0.203 in raw IM to 0.185 for IM-493 and to 0.132 for IM-573. The change in the $\mathrm{O} / \mathrm{C}$ ratio indicates that oxygen functional groups decreased during hydrothermal treatment with increasing treatment temperature. The IM improved during hydrothermal treatment, especially with treatment above a temperature of $493 \mathrm{~K}$. The ratio of $\mathrm{H} / \mathrm{C}$ increased with increasing temperature below $513 \mathrm{~K}$. The data showed that hydrothermal treatment promotes the removal of oxygen functional groups, and hydrogen is exchanged and transferred between water and lignite. The hydrogen bonds in lignite were rearranged during hydrothermal treatment. When the treatment temperature subsequently increased, the H/C ratio decreased.

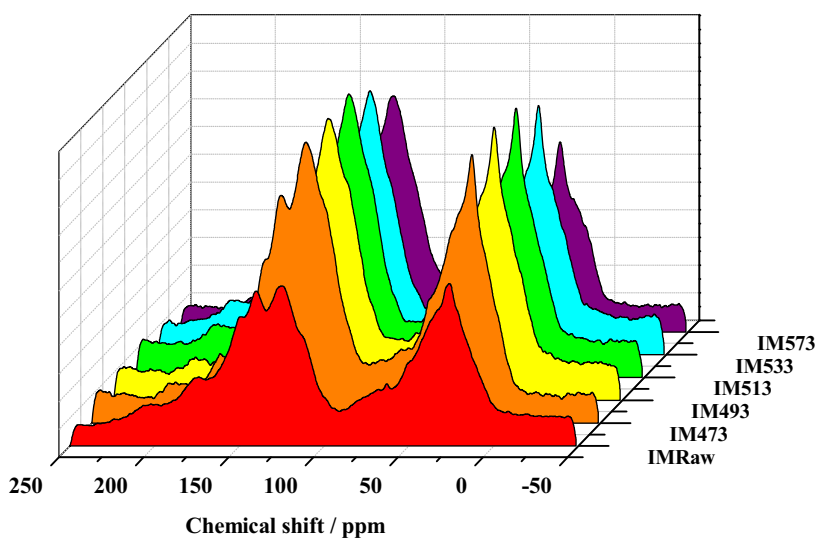

Fig. $3{ }^{13} \mathrm{C}$ NMR spectra of raw and treated IM

\subsection{Evolution of different types of carbon in IM during hydrothermal treatment}

To investigate the change of the IM structure during hydrothermal treatment in detail, the structure of the carbon skeleton of the raw and treated IM was analyzed via solid ${ }^{13} \mathrm{C}$-NMR spectroscopy, and the spectra are shown in Fig. 3.

Two peak clusters containing various functional groups of structural carbons, rather than unique sharp peaks with specific chemical shifts were observed. They were visible in the spectrum as: aliphatic units (0-90 ppm), aromatic units (100-165 ppm), and carbonyl units were observed at a chemical shift of 170-220 ppm. The spectra were fitted to quantify the relative proportions of different carbon types in the raw and treated IM, as shown in Fig. 4.

The relative contents of each carbon unit to the total carbon content are calculated by their individual areas from the fitted ${ }^{13} \mathrm{C}$ NMR spectra and listed in Table 2.

The data in Table 2 indicate the difference between the structural characteristics of raw and treated IM can be given as: an increase of aliphatic carbons, a decrease of ether and changes of carboxyl, quinone, and carbonyl carbons after treatment.

\subsubsection{Oxygen-linked carbon species $\left(f_{a l}^{O}, f_{a}^{O}\right.$, and $\left.f_{a}^{C C}\right)$}

The functional groups of oxygen were abundant in the raw IM (oxygen-linked carbon is $27.40 \%$ ), as characterized by oxygen aliphatic carbon $\left(\mathrm{f}_{\mathrm{al}}^{\mathrm{O}}\right)$, oxygen aromatic carbon $\left(\mathrm{f}_{\mathrm{a}}^{\mathrm{O}}\right)$, and carboxyl, quinone, and carbonyl carbon $\left(\mathrm{f}_{\mathrm{a}}^{\mathrm{CC}}\right)$. There was a decrease in $\mathrm{f}_{\mathrm{al}}^{\mathrm{O}}$ with increasing treatment temperature. The $\mathrm{f}_{\mathrm{a}}^{\mathrm{O}}$ decreased from $12.89 \%$ of raw IM to $4.26 \%$ in IM493 , and then increased to $8.16 \%$ for IM-533. The change of $\mathrm{f}_{\mathrm{a}}^{\mathrm{CC}}$ had the same trend as for $\mathrm{f}_{\mathrm{a}}^{\mathrm{O}}$. The results indicate that hydrothermal treatment promotes the cleavage of ether, and steam could also depolymerize the lignite macromolecular network via cleavage of weak covalent bonds, 

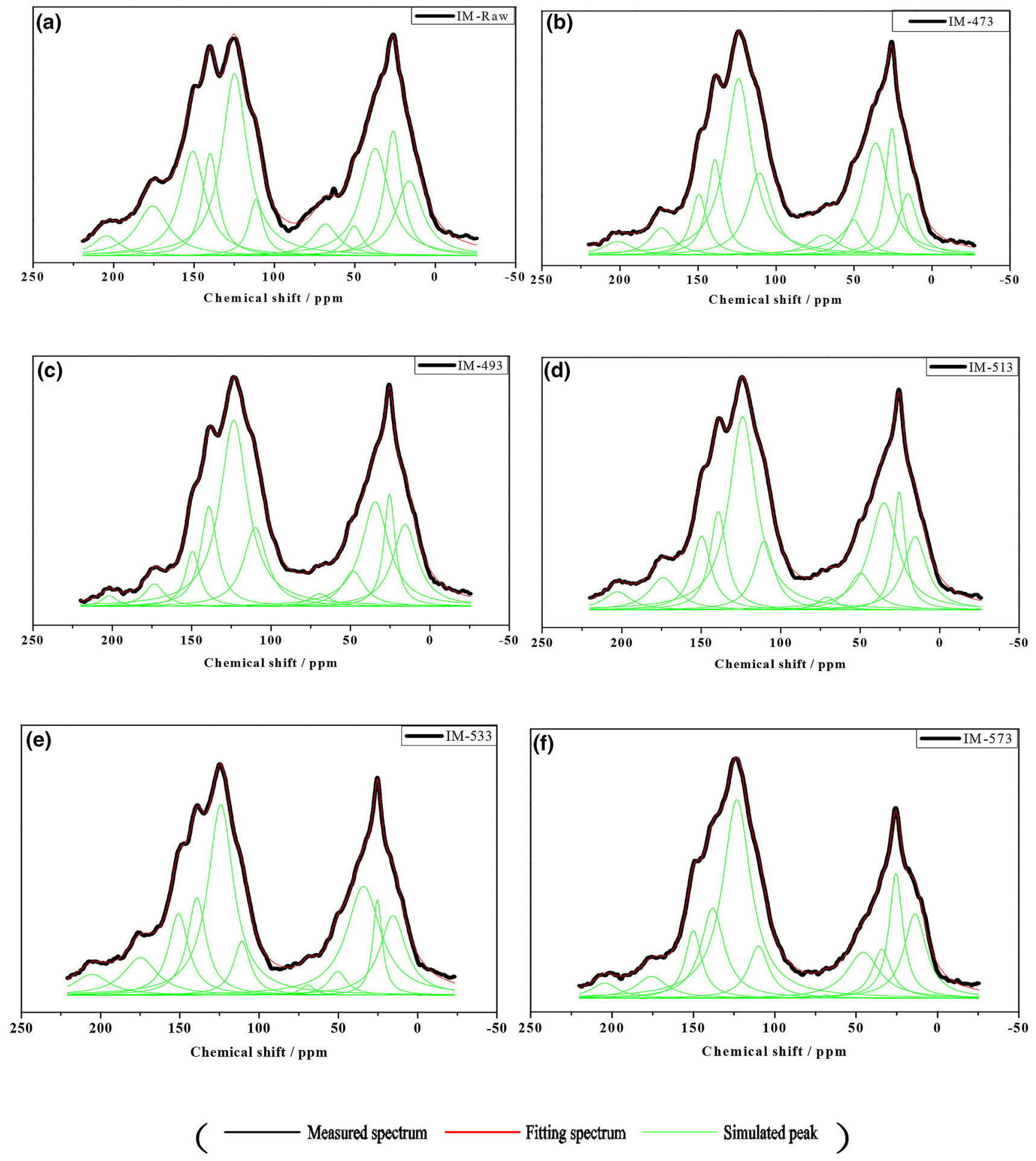

Fig. 4 Fitted ${ }^{13} \mathrm{C}$ NMR spectra of the raw and treated IM (Black line is measured spectrum, red line is fitting spectrum, green line is simulated peak)

such as ether linkages that are thermally stable but hydrothermally unstable at elevated temperatures (Zeng et al. 2006). Water with the presence of oxygen functional groups in lignite can participate in one or more roles: as a catalyst, reactant, and solvent in aquathermolysis chemistry at a high temperature ( $~ 523 \mathrm{~K}$ ) (Siskina and Katritzky 2000). Therefore, the $\mathrm{O} / \mathrm{C}$ ratio and $\mathrm{f}_{\mathrm{al}}^{\mathrm{O}}$ and $\mathrm{f}_{\mathrm{a}}^{\mathrm{O}}$ decreased and $\mathrm{f}_{\mathrm{a}}^{\mathrm{CC}}$ changed. Hydrothermal treatment can be divided into three stages. (1) At a temperature $<493 \mathrm{~K}$, thermal decomposition of carboxyl acid, breaking of the alkyl 
Table 2 Carbon structure distributions of the raw and treated IM on the basis of the raw lignite

\begin{tabular}{llrrrrrrrrrr}
\hline Sample & Carbon yield $(\%)$ & $\mathrm{f}_{\mathrm{al}}^{3}(\%)$ & $\mathrm{f}_{\mathrm{al}}^{\mathrm{a}}(\%)$ & $\mathrm{f}_{\mathrm{al}}^{2}(\%)$ & $\mathrm{f}_{\mathrm{al}}^{1}+\mathrm{f}_{\mathrm{al}}^{*}(\%)$ & $\mathrm{f}_{\mathrm{al}}^{\mathrm{O}}(\%)$ & $\mathrm{f}_{\mathrm{a}}^{\mathrm{H}}(\%)$ & $\mathrm{f}_{\mathrm{a}}^{\mathrm{B}}(\%)$ & $\mathrm{f}_{\mathrm{a}}^{\mathrm{S}}(\%)$ & $\mathrm{f}_{\mathrm{a}}^{\mathrm{O}}(\%)$ & $\mathrm{f}_{\mathrm{a}}^{\mathrm{CC}}(\%)$ \\
\hline $\mathrm{IM}$ & - & 10.08 & 10.38 & 14.87 & 2.39 & 4.00 & 3.89 & 23.04 & 7.95 & 12.89 & 10.51 \\
$\mathrm{IM}-473$ & 94.15 & 7.18 & 9.34 & 15.24 & 3.56 & 3.27 & 11.01 & 25.73 & 7.92 & 5.22 & 5.69 \\
$\mathrm{IM}-493$ & 93.63 & 10.98 & 6.92 & 15.59 & 4.31 & 1.53 & 9.99 & 27.76 & 9.00 & 4.26 & 3.31 \\
$\mathrm{IM}-513$ & 92.15 & 8.64 & 6.87 & 15.32 & 4.58 & 1.25 & 6.88 & 26.43 & 8.14 & 6.95 & 7.09 \\
$\mathrm{IM}-533$ & 91.94 & 10.32 & 4.47 & 18.36 & 2.14 & 0.69 & 4.55 & 24.24 & 9.09 & 8.16 & 9.91 \\
$\mathrm{IM}-573$ & 90.53 & 10.03 & 9.18 & 4.92 & 8.02 & 0.13 & 5.70 & 29.71 & 11.22 & 5.88 & 5.74 \\
\hline
\end{tabular}

ether, and the slight cleavage of the aryl ether are thought to be the main reactions ( $\mathrm{Li}$ et al. 2013). In this stage, $\mathrm{f}_{\mathrm{al}}^{\mathrm{O}}$, $\mathrm{f}_{\mathrm{a}}^{\mathrm{O}}$, and $\mathrm{f}_{\mathrm{a}}^{\mathrm{CC}}$ decrease, and then the hydrogen bond is weakened. (2) The stage between 493 and $533 \mathrm{~K}$, here, the hydrogen bond between lignite and water is broken ( $\mathrm{Li}$ et al. 2011), and the interaction of lignite and water tends to occur. The free $\mathrm{H}^{+}$and $\mathrm{OH}^{-}$are possibly cross-linked to the benzene or phenoxy groups to generate phenolic groups via electrophilic substitution, and $\mathrm{f}_{\mathrm{a}}^{\mathrm{O}}$ increases. Because of the mineral matter present in lignite, lignite was enclosed in an acidic environment after the addition of water (Shui et al. 2006). The weak covalent bonds were catalyzed for cleavage, hence, $\mathrm{f}_{\mathrm{al}}^{\mathrm{O}}$ continued to decrease. Furthermore, water was adsorbed around the oxygen functional groups (Xiang et al. 2014) to produce a new hydrogen bond, and the raw IM hydrogen bond between the hydroxyl was broken to obtain a free hydroxyl (Miura et al. 1991), which resulted in a rearrangement of the hydrogen bond. The free hydroxyl condensed to obtain quinone, so $\mathrm{f}_{\mathrm{a}}^{\mathrm{CC}}$ increased and the $\mathrm{H} / \mathrm{C}$ ratio decreased. (3) At temperatures $>533 \mathrm{~K}$, a cleavage of the covalent bond may occur (Shi et al. 2013), the ether bond is broken further, and the carboxyl, quinone, and carbonyl groups begin to break under the steam pressure. When the temperature was increased to $573 \mathrm{~K}, \mathrm{f}_{\mathrm{al}}^{\mathrm{O}}$ decreased from $0.69 \%$ in IM-533 to $0.13 \%$ in $\mathrm{IM}-573, \mathrm{f}_{\mathrm{a}}^{\mathrm{O}}$ decreased from $8.16 \%$ in IM-533 to $5.88 \%$ in IM-573 $\mathrm{m}$, and $\mathrm{f}_{\mathrm{a}}^{\mathrm{CC}}$ decreased from $9.91 \%$ in IM-533 to $5.74 \%$ in IM-573.

\subsubsection{Aromatic carbon species $\left(f_{a}^{H}, f_{a}^{B}, f_{a}^{S}\right.$, and $\left.f_{a}^{O}\right)$}

The aromatic carbon species comprises $\sim 50 \%$ at the treated temperature below $533 \mathrm{~K}$. While the main lignite structure displays minimal change with hydrothermal treatment below $533 \mathrm{~K}$, the protonated aromatic carbon and side chains markedly changed. The ratios of the protonated aromatic carbon, bridging ring junction aromatic carbon, and aliphatic substituted aromatic carbon to the total aromatic carbon are shown in Fig. 5.

From Fig. 5, it can be seen that the decomposition of the carboxyl is a primary reaction during the first stage of

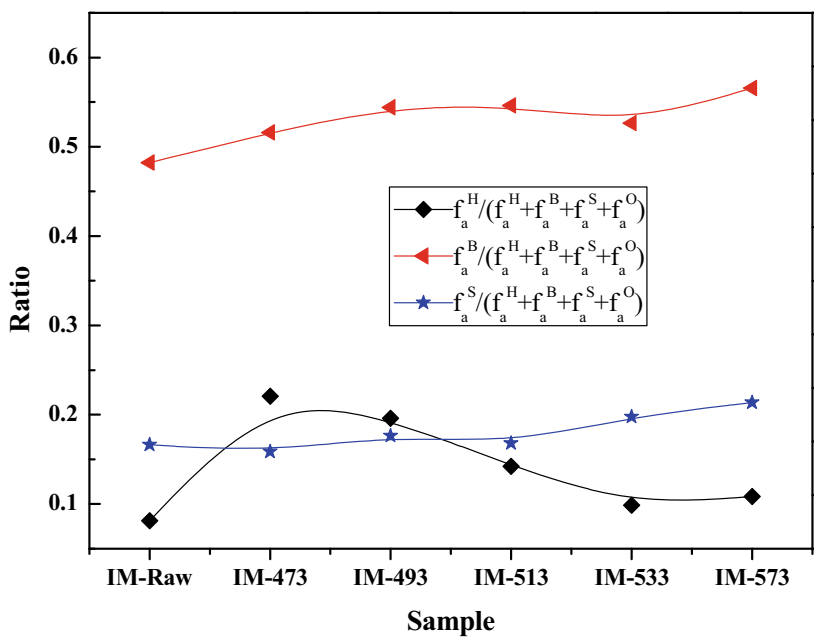

Fig. 5 Variation of the ratio of protonated aromatic carbon, bridging ring junction aromatic carbon, and aliphatic substituted aromatic carbon to the aromatic carbon

hydrothermal treatment. The $\mathrm{f}_{\mathrm{a}}^{\mathrm{H}}$ increased, while $\mathrm{f}_{\mathrm{a}}^{\mathrm{B}}$ and $\mathrm{f}_{\mathrm{a}}^{\mathrm{S}}$ had only a small change. The $\mathrm{H} / \mathrm{C}$ increased in the first stage according to Fig. 1, which is consistent with the analysis for oxygen-linked carbon. In the second and third stages, the free radical in lignite increased because of the hydrolysis of the oxygen functional groups. A cross-linking reaction occurred between the free radicals under aqueous conditions. The aliphatic hydrocarbon radical may be linked with the aryl radical at elevated temperature and the ratio of $\mathrm{f}_{\mathrm{a}}^{\mathrm{S}}$ to aromatic carbon increased from 0.176 in IM493 to 0.214 in IM-573, and the ratio of $\mathrm{f}_{\mathrm{a}}^{\mathrm{H}}$ to aromatic carbon decreased from 0.196 in IM-493 to 0.109 in IM573 .

\subsubsection{Aliphatic carbon species $\left(f_{a l}^{3}, f_{a l}^{a}, f_{a l}^{2}, f_{a l}^{l}\right.$, and $\left.f_{a l}^{*}\right)$}

From the data in Table 2, it can be seen that the total aliphatic carbon changes a little $(\sim 35 \%)$. However, the ratio of $\mathrm{CH}_{2} / \mathrm{CH}_{3}\left(\mathrm{f}_{\mathrm{al}}^{2} /\left(\mathrm{f}_{\mathrm{al}}^{3}+\mathrm{f}_{\mathrm{al}}^{\mathrm{a}}\right)\right)$ increased from 0.727 in IM to 1.241 in IM-533 (Fig. 6) in the second stage, and it decreased from 1.241 in IM-533 to 0.256 in IM-573 in the third stage. 


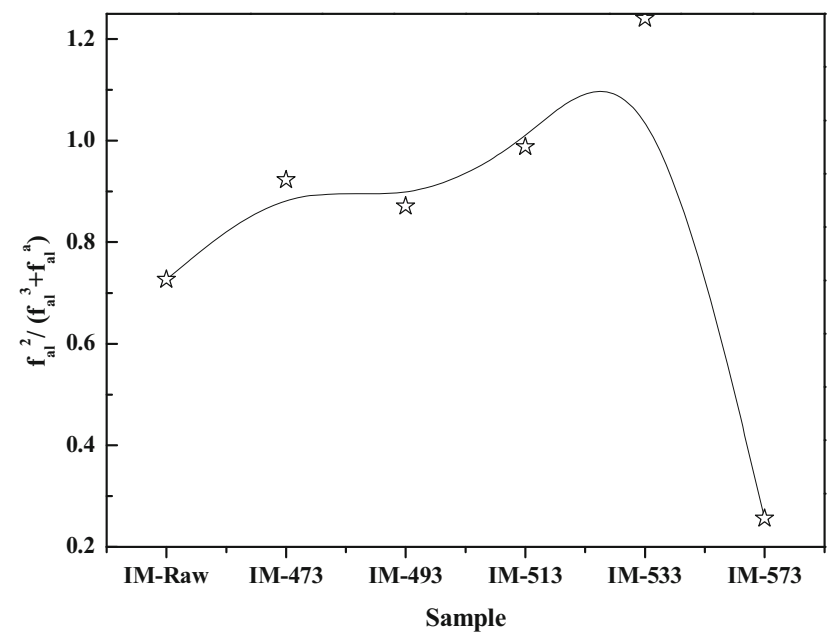

Fig. 6 Variation of the $\mathrm{CH}_{2} / \mathrm{CH}_{3}$ ratio

The $\mathrm{CH}_{2} / \mathrm{CH}_{3}$ ratio can be considered to be an estimate of the length of the aliphatic chains of lignite and a branching index (Ibarra et al. 1996). In the first stage, the increase of methylene is due to the decomposition of oxygen functional groups, hence, $\mathrm{H} / \mathrm{C}$ increases; however, the increasing trend is not obvious. The $\mathrm{CH}_{2} / \mathrm{CH}_{3}$ ratio clearly increases in the second stage because hydrolysis of the oxygen functional groups (such as carboxyl, esters, and ethers) plays an important role in this stage. The hydrogen of the functional groups in lignite can exchange with water via electrophilic substitution on addition of water at this temperature (Ishihara et al. 1993, 2002), and then transfer in lignite or the methyl hydroaromatic structures opposite to the branched aliphatic structures. The $\mathrm{H}$ radicals produced by the condensation of free phenol also participate in the hydrogen transfer. However, a portion of the covalent bonds of $\mathrm{C}-\mathrm{C}$ begin to break in the third stage and the length of the aliphatic carbon decreases. The length of the aliphatic chain is smaller when the treatment temperature rises to $573 \mathrm{~K}$. The composition of the gas produced during hydrothermal treatment was analyzed via GC and the results are presented in Table 3.

The decomposition and hydrolysis of the oxygen functional group is the primary reaction occurring below $533 \mathrm{~K}$ during the hydrothermal treatment. The largest gas components are $\mathrm{CO}_{2}$ and $\mathrm{CO}$. Hydrogen transfer reaction

Table 3 Composition of the gas produced during the hydrothermal treatment

\begin{tabular}{lllll}
\hline Temperature $(\mathrm{K})$ & $\mathrm{CO}_{2}(\%)$ & $\mathrm{CO}(\%)$ & $\mathrm{H}_{2}(\%)$ & $\mathrm{CH}_{4}(\%)$ \\
\hline 493 & 97.64 & 2.18 & 0.18 & $\sim 0$ \\
533 & 96.45 & 2.62 & 0.83 & 0.10 \\
573 & 95.56 & 3.00 & 1.16 & 0.28 \\
\hline
\end{tabular}

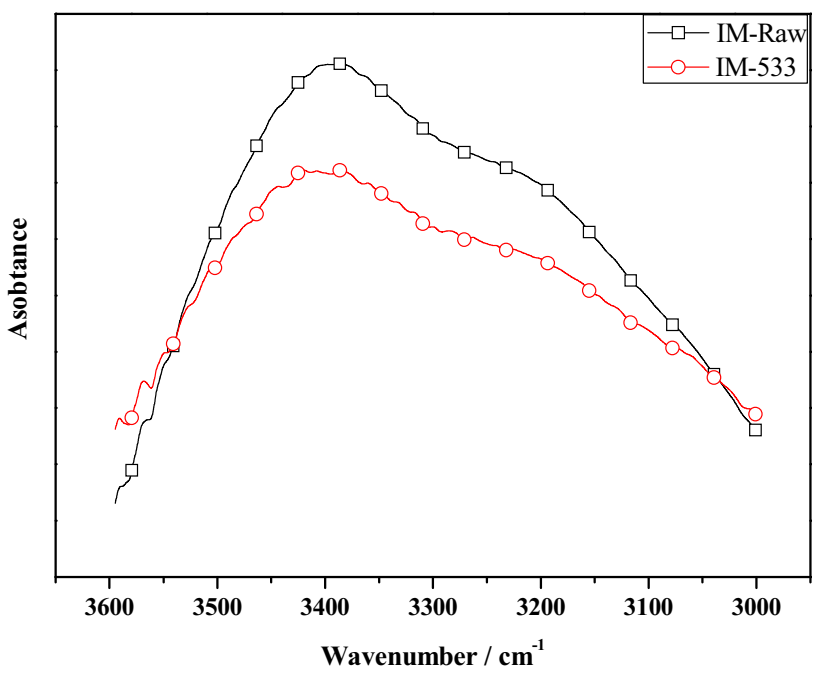

Fig. 7 Comparison of IM-Raw and IM-533 spectra in the region $3000-3500 \mathrm{~cm}^{-1}$

occurs in the second stage, here, the production of $\mathrm{H}_{2}$ during hydrothermal treatment increases from $0.18 \%$ at $493 \mathrm{~K}$ to $0.83 \%$ at $533 \mathrm{~K}$. The cleavage of covalent bonds leads to an increase in the $\mathrm{CO}$ and $\mathrm{CH}_{4}$ components of the gas in the third stage, which indicates that the length of the aliphatic carbon decreased. These results are consistent with the previously discussed analyses.

\subsection{FTIR analysis of the evolution of oxygen functional groups during hydrothermal treatment}

To verify the objectives discussed above, the functional groups of IM-Raw and IM-533 were monitored via FTIR. The $3000-3500 \mathrm{~cm}^{-1}$ region of the IM-Raw and IM-533 spectra were compared using the absorption of the $\mathrm{C}=\mathrm{C}$ bond stretching of the aromatic ring at $1588 \mathrm{~cm}^{-1}$ as a standard peak, and the obtained spectra are shown in Fig. 7.

A decrease in the intensity of the band near $3300 \mathrm{~cm}^{-1}$ can be seen in the spectrum in Fig. 7. This indicates that the hydrogen bond decreased during the hydrothermal treatment of lignite because of hydrolysis of the oxygen functional group. While water absorbed in $\mathrm{KBr}$ may obscure this band, the results agree with Ishihara et al. (2002) and Yan et al. (2020) and the discussion above.

The oxygen functional groups (region of $1000-1750 \mathrm{~cm}^{-1}$ ) were analyzed via curve-fitting and the results are shown in Fig. 8.

The content of each oxygen functional group unit relative to the total simulated peak area in the region of $1000-1750 \mathrm{~cm}^{-1}$ was determined from the fitted spectra; the results for IM-533 were calculated based on the raw lignite listed in Table 4. 

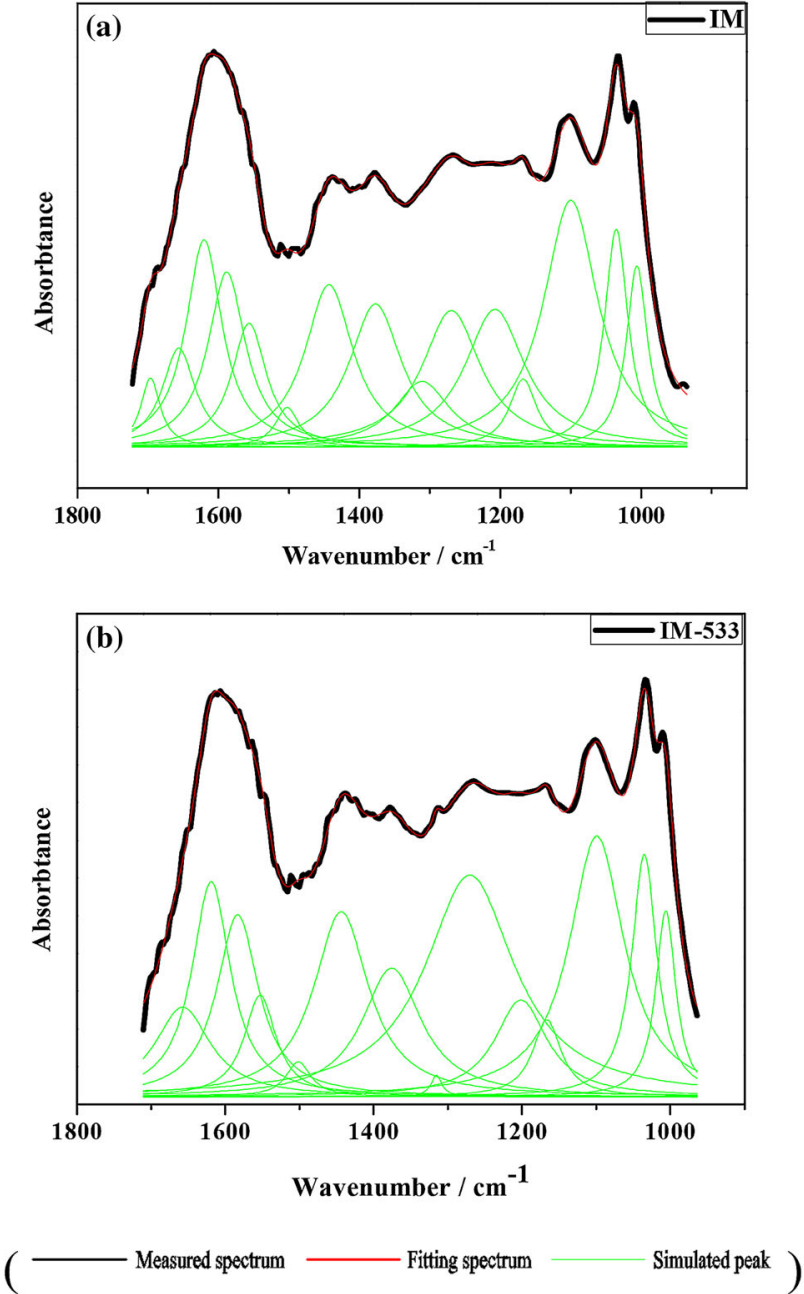

Fig. 8 Fitted FTIR spectra of the oxygen functional group in IMRaw and IM-533 (Black line is measured spectrum, red line is fitting spectrum, green line is simulated peak)

The main oxygen functional groups in IM are aryl ether, phenol, and carbonyl or quinone conjugated with aromatic rings. Hydrothermal treatment promotes the cleavage of weak bonds such as the ether and carboxyl, resulting in a decrease in the amount of ether and carboxyl groups. With the addition of water, the free $\mathrm{H}$ and $\mathrm{OH}$ possibly cross-link with the benzene or phenoxy groups to generate phenol via electrophilic substitution in the second stage. Hence, the area percentage in $1269 \mathrm{~cm}^{-1}$, assigned to phenolic groups, clearly increases from $9.60 \%$ in IM to $18.51 \%$ in IM-533. With decreasing hydrogen bonds and increasing free phenol, quinone is produced and takes part in hydrogen transfer between water and lignite. Therefore, the conjugated $\mathrm{C}=\mathrm{O}$ increases according to the stretching band at $1656 \mathrm{~cm}^{-1}$. The results of the FTIR characterization were in good agreement with the NMR analysis.
From these results, it can be concluded that the hydrothermal treatment proceeds in three stages: the first stage is the reaction involving the decomposition of the carboxyl, non-covalent bond and weak covalent bond; the second stage is hydrolysis of the oxygen functional groups and hydrogen transfer between water and lignite; and the third stage is the breakage of covalent bonds. The evolution of the lignite structure is described in Fig. 9.

\section{Conclusions}

In this work, the evolution of the IM lignite structure during hydrothermal treatment was investigated via solid ${ }^{13} \mathrm{C}$ NMR and FTIR spectroscopies. The carbon content increased from $72.99 \mathrm{wt} \%$ in IM to $78.16 \mathrm{wt} \%$ in IM-573. The atomic ratio of $\mathrm{O} / \mathrm{C}$ decreased from 0.203 in IM to 0.132 in IM-573. The hydrothermal treatment resulted in improvement of the IM. The structural evolution of IM during hydrothermal treatment can be divided into three stages depending on the treatment temperature:

(1) In the first stage $(<493 \mathrm{~K})$, oxygen functional groups decompose and are substituted by hydrogen with increasing temperature. The atomic ratio of $\mathrm{H} / \mathrm{C}$ increased from 0.764 in IM to 0.920 in IM-493, and oxygen-linked carbon decreased from $27.40 \%$ in IM to $9.10 \%$ in IM-493. The main components of the escaping gas were $\mathrm{CO}_{2}$ with a small amount of $\mathrm{CO}$; In the second stage (493-533 K), the hydrolysis of functional groups promoted cleavage of weak bonds. $\mathrm{H}^{+}$and $\mathrm{OH}^{-}$were linked by lignite via an ionic pathway under hydrothermal conditions. The oxygen-linked aromatic carbon increased from $4.26 \%$ in IM-493 to $8.16 \%$ in IM-533, and the phenolic groups increased, as indicated by the FTIR spectra. Hydrogen transfer took place between the water and lignite or within the intra-molecular structure. The hydroaromatic methyl structure converted to a branched aliphatic structure, resulting in an increase of the $\mathrm{CH}_{2} / \mathrm{CH}_{3}$ ratio from 0.871 in IM-493 to 1.241 in IM-533. The free phenolic group was condensed to generate quinonyl and the carbonyl carbon increased from $3.31 \%$ in IM-493 to $9.91 \%$ in IM533; the $\mathrm{H} / \mathrm{C}$ ratio had a small decrease. $\mathrm{H}_{2}$ and $\mathrm{CH}_{4}$ were eliminated in this stage.

(3) In the third stage $(>533 \mathrm{~K})$, a portion of the covalent bonds begin to break. The $\mathrm{CH}_{2} / \mathrm{CH}_{3}$ ratio decreased and the hydroaromatic methyl structure content increased. The conjugated $\mathrm{C}=\mathrm{O}$ in lignite also decomposed to produce $\mathrm{CO}$ and the carbonyl carbon decreased from $9.91 \%$ in IM-533 to $5.74 \%$ in IM-573. The content of $\mathrm{CO}$ and $\mathrm{CH}_{4}$ in the escaping 
Table 4 Relative contents of each oxygen functional group

\begin{tabular}{lllll}
\hline Peak & Position $\left(\sigma / \mathrm{cm}^{-1}\right)$ & Assignment & IM area percentage $(\%)$ & IM-533 area percentage $(\%)$ \\
\hline 1 & 1005 & Ash & 4.64 & 3.50 \\
2 & 1035 & Alkyl ethers & 6.11 & 5.68 \\
3 & 1100 & Aryl ethers & 16.05 & 13.50 \\
4 & 1167 & C-O phenol & 2.21 & 2.08 \\
5 & 1207 & C-O phenol & 9.90 & 4.77 \\
6 & 1269 & C-O phenol & 9.60 & 18.51 \\
7 & 1310 & C-O phenol & 4.40 & 0.22 \\
8 & 1376 & CH3-Ar & 9.00 & 7.17 \\
9 & 1442 & CH, CH & 9.43 & 9.56 \\
10 & 1502 & Aromatic C=C & 1.12 & 0.81 \\
11 & 1556 & Aromatic C=C & 5.16 & 3.04 \\
12 & 1588 & Aromatic C=C & 7.87 & 7.20 \\
13 & 1620 & Conjugated C=O & 8.94 & 7.80 \\
14 & 1656 & Conjugated C=O & 3.94 & 4.73 \\
15 & 1696 & Carboxyl acids & 1.61 & 0 \\
& Total & & 100 & 88.57 \\
\hline
\end{tabular}
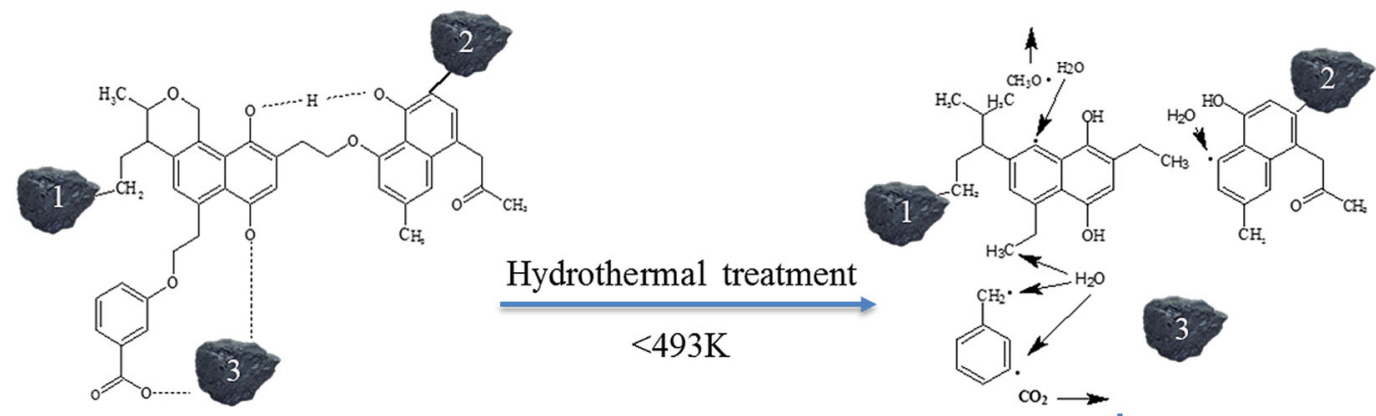

Hydrothermal treatment
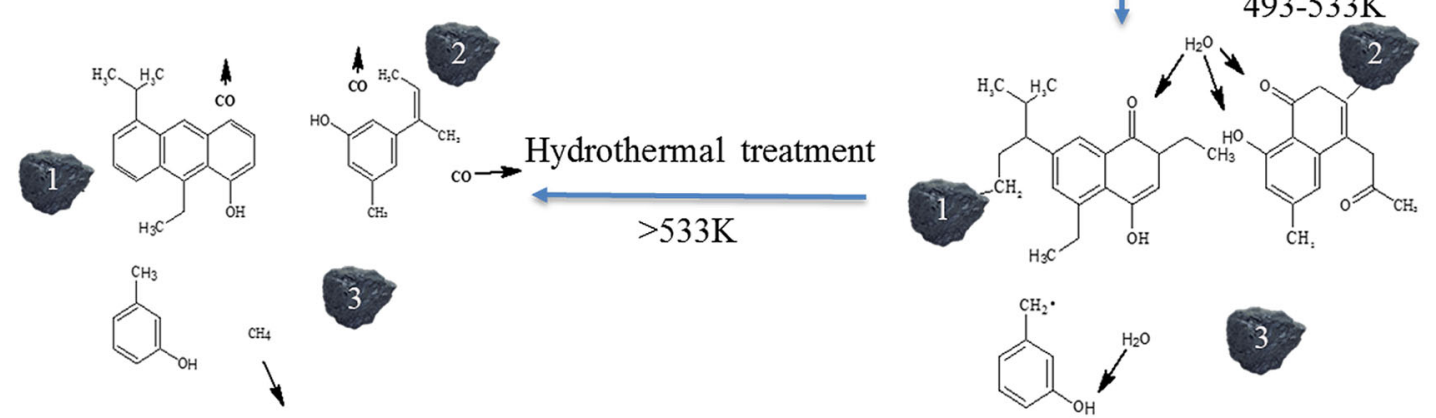

Fig. 9 Schematic of the structural evolution of IM lignite during hydrothermal treatment

gas also increased. The bridge ring junction carbon content increased from $24.24 \%$ in IM-533 to $29.71 \%$ in IM-573. At this stage, the changes in the lignite structure were clear.
Acknowledgments This study was funded by National Key Basic Research Development Program of China (973Program, No. 2011CB201304), Natural Science Foundation of China (51906021 and 51703014), National Key R\&D Program of China (2018YFC1901203), Research Foundation for Advanced Talents of Jiangsu University (16JDG022) and Changzhou University 
(ZMF17020034), Natural Science Foundation of Colleges in Jiangsu Province (19KJB480005), Changzhou Applied Basic Research Plan (CJ20190081), and Science and Technology Project of Guangdong Province, PR China (No. 2016A010105017) and (No. 2017B040404009).

Open Access This article is licensed under a Creative Commons Attribution 4.0 International License, which permits use, sharing, adaptation, distribution and reproduction in any medium or format, as long as you give appropriate credit to the original author(s) and the source, provide a link to the Creative Commons licence, and indicate if changes were made. The images or other third party material in this article are included in the article's Creative Commons licence, unless indicated otherwise in a credit line to the material. If material is not included in the article's Creative Commons licence and your intended use is not permitted by statutory regulation or exceeds the permitted use, you will need to obtain permission directly from the copyright holder. To view a copy of this licence, visit http://creativecommons. org/licenses/by/4.0/

\section{References}

Butler CJ, Green AM, Chaffee AL (2007) The fate of trace elements during MTE and HTD dewatering of Latrobe Valley brown coals. Coal Prep 27(4):210-229

Erdenetsogt BO, Lee I, Lee SK, Ko YJ, Bat-Erdene D (2010) Solidstate C-13 CP/MAS NMR study of Baganuur coal, Mongolia: oxygen-loss during coalification from lignite to subbituminous rank. Int J Coal Geol 82(1-2):37-44

Feng L, Yuan C, Mao L, Yan C, Jiang X, Liu J, Liu X (2008) Water occurrence in lignite and its interaction with coal structure. Fuel 219:288-295

Fu J, Wang J (2014) Enhanced slurryability and rheological behaviors of two low-rank coals by thermal and hydrothermal pretreatments. Powder Technol 266:183-190

Ge L, Feng H, Xu C, Zhang Y, Wang Z (2018) Effect of hydrothermal dewatering on the pyrolysis characteristics of Chinese low-rank coals. Appl Therm Eng 141:70-78

Ibarra JV, Muñoz E, Moliner R (1996) FTIR study of the evolution of coal structure during the coalification process. Org Geochem 24(6):725-735

Inoue T, Okuma O, Masuda K, Yasumuro M, Miura K (2012a) Hydrothermal treatment of brown coal to improve the space time yield of a direct liquefaction reactor. Energy Fuels 26(4):2198-2203

Inoue T, Okuma O, Masuda K, Yasumuro M, Miura K (2012b) Direct liquefaction of brown coal using a 0.1 ton/day process development unit: effect of hydrothermal treatment on scale deposition and liquefaction yield. Energy Fuels 26(9):5821-5827

Ishihara A, Takaoka H, Nakajima E, Imai Y, Kabe T (1993) Estimation of hydrogen mobility in coal using a tritium tracer method. Hydrogen exchange reactions of coals with tritiated water and molecular hydrogen. Energy Fuels 7(3):362-366

Ishihara A, Nishigori D, Saito M, Sturisna IP, Qian W, Kabe T (2002) Elucidation of hydrogen mobility in functional groups of coals using tritium tracer methods. Energy Fuels 16(1):32-39

Jiang J, Yang W, Cheng Y, Liu Z, Zhang Q, Zhao K (2019) Molecular structure characterization of middle-high rank coal via XRD, Raman and FTIR spectroscopy: implications for coalification. Fuel 239:559-572

Katalambula H, Gupta R (2009) Low-Grade coals: a review of some prospective upgrading technologies. Energy Fuels 23(7):3392-3405
Li W, Bai ZQ, Bai J, Guo ZX (2011) Decomposition kinetics of hydrogen bonds in coal by a new method of in situ diffuse reflectance FT-IR. J Fuel Chem Technol 39(5):321-327

Li MF, Zeng FG, Chang HZ, Xu BS, Wang W (2013) Aggregate structure evolution of low-rank coals during pyrolysis by in situ X-ray diffraction. Int J Coal Geol 116-117:262-269

Li H, Wu S, Wu Y, Wang H, Zhang Z, Huang S, Gao J (2020) Effects of hydrothermal treatment on physico-chemcial structures and liquefaction behaviors of lignite. Fuel 263:116636

Liu XF, You JL, Wang YY, Lu LM, Xie YF, Yu LW, Fu Q (2014) Raman spectroscopic study on the pyrolysis of Australian bituminous coal. J Fuel Chem Technol 42(3):270-276

Liu P, Wang L, Zhou Y, Pan T, Lu X, Zhang D (2016) Effect of hydrothermal treatment on the structure and pyrolysis product distribution of Xiaolongtan lignite. Fuel 164:110-118

Liu P, Le J, Zhang D, Wang S, Pan T (2017) Free radical reaction mechanism on improving tar yield and quality derived from lignite after hydrothermal treatment. Fuel 207:244-252

Miura K, Mae K, Yoshimura T, Masuda K, Hashimoto K (1991) Mechanism of radical transfer during the flash pyrolysis of solvent-swollen coal. Energy Fuels 5(6):803-808

Safarova M, Kusy J, Andel L (2005) Pyrolysis of brown coal under different process conditions. Fuel 84(17):2280-2285

Sakaguchi M, Laursen K, Nakagawa H, Miura K (2008) Hydrothermal upgrading of Loy Yang brown coal-effect of upgrading conditions on the characteristics of the products. Fuel Process Technol 89(4):391-396

Shi L, Liu QY, Guo XJ, Wu WZ, Liu ZY (2013) Pyrolysis behavior and bonding information of coal-A TGA study. Fuel Process Technol 108:125-132

Shui H, Wang Z, Wang G (2006) Effect of hydrothermal treatment on the extraction of coal in the $\mathrm{CS}_{2} / \mathrm{NMP}$ mixed solvent. Fuel 85(12-13): 1798-1802

Siskina M, Katritzky AR (2000) A review of the reactivity of organic compounds with oxygen-containing functionality in superheated water. J Anal Appl Pyrolysis 54(1-2):193-214

Sonibare OO, Haeger T, Foley SF (2010) Structural characterization of Nigerian coals by X-ray diffraction, Raman and FTIR spectroscopy. Energy 35:5347-5353

Sun Q, Li W, Chen H, Li B (2004) The $\mathrm{CO}_{2}$-gasification and kinetics of Shenmu maceral chars with and without catalyst. Fuel 83(2):1787-1793

Ullah H, Liu G, Yousaf B, Ali MU, Abbas Q, Zhou C, Rashid A (2018) Hydrothermal dewatering of low-rank coals: influence on the properties and combustion characteristics of the solid products. Energy 158:1192-1203

Wang SQ, Tang YG, Schobert HH, Guo YN, Su YF (2011) FTIR and ${ }^{13} \mathrm{C}$ NMR investigation of coal component of Late Permian coals from southern China. Energy Fuels 25(12):5672-5677

Wang SQ, Tang YG, Schobert HH, Guo YN, Su YF (2013a) Petrology and structural studies in liquefaction reactions of late permian coals from Southern China. Fuel 107:518-524

Wang SQ, Tang YG, Schobert HH, Guo YN, Gao WC, Lu XK (2013b) FTIR and simultaneous TG/MS/FTIR study of Late Permian coals from Southern China. J Anal Appl Pyrolysis 100:75-80

Wang LL, Pan TY, Liu P, Zhang DX (2016a) Hydrogen transfer route during hydrothermal treatment lignite using isotope tracer method and improving the pyrolysis tar yield. Energy Fuels. https://doi.org/10.1021/acs.energyfuels.6b00281

Wang Z, Li Q, Lin Z, Whiddon R, Qiu K, Kuang M, Cen K (2016b) Transformation of nitrogen and sulphur impurities during hydrothermal upgrading of low quality coals. Fuel 164:254-261

Wei ZB, Gao XX, Zhang DJ, Da J (2005) Assessment of thermal evolution of kerogen geopolymers with their structural 
parameters measured by solid-state ${ }^{13} \mathrm{C}$ NMR spectroscopy. Energy Fuels 19(1):240-250

Wu D, Liu GJ, Sun RY, Fan X (2013) Investigation of structural characteristics of thermally metamorphosed coal by FTIR spectroscopy and X-ray diffraction. Energy Fuels 27(9):5823-5830

Wu D, Liu GJ, Sun RY (2014) Investigation on structural and thermodynamic characteristics of perhydrous bituminous coal by fourier transform infrared spectroscopy and thermogravimetry/mass spectrometry. Energy Fuels 28(3):3024-3035

Xiang JH, Zeng FG, Li B, Zhang L, Li MF, Liang HZ (2013) Construction of macromolecular structural model of anthracite from Chengzhuang coal mine and its molecular simulation. J Fuel Chem Technol 41(4):391-399

Xiang JH, Zeng FG, Liang HZ, Li B, Song XX (2014) Molecular simulation of the $\mathrm{CH}_{4} / \mathrm{CO}_{2} / \mathrm{H}_{2} \mathrm{O}$ adsorption onto the molecular structure of coal. Sci China Earth Sci 57(8):1749-1759

Yan JH, Bai ZQ, Bai J, Guo ZX, Li W (2014) Effects of organic solvent treatment on the chemical structure and pyrolysis reactivity of brown coal. Fuel 128:39-45

Yan J, Lei Z, Li Z, Wang Z, Ren S, Kang S, Wang X, Shui H (2020) Molecular structure characterization of low-medium rank coals via XRD, solid state $13 \mathrm{C}$ NMR and FTIR spectroscopy. Fuel 268:117038
Yu Y, Liu J, Wang R, Zhou J, Cen K (2012) Effect of hydrothermal dewatering on the slurryability of brown coals. Energ. Convers Manag 57:8-12

Yu YJ, Liu JZ, Cen KF (2014) Properties of coal water slurry prepared with the solid and liquid products of hydrothermal dewatering of brown coal. Ind Eng Chem Res 53(11):4511-4517

Zeng C, Favas G, Wu HW, Chaffee AL, Hayashi JI, Li CZ (2006) Effects of pretreatment in steam on the pyrolysis behavior of loy yang brown coal. Energy Fuels 20(1):281-286

Zhang D (2014) Fundamental and application of coal to oil technologies. Shanghai Scientific and Technical Publishers, Shanghai, p 15

Zhang D, Liu P, Lu X, Wang L, Pan T (2016) Upgrading of low rank coal by hydrothermal treatment: coal tar yield during pyrolysis. Fuel Process Technol 141(part 1):117-122

Zhang XP, Zhang C, Tan P, Li X, Fang QY, Chen G (2018) Effects of hydrothermal upgrading on the physicochemical structure and gasification characteristics of Zhundong coal. Fuel Process Technol 172:200-208

Zhao P, Huang N, Li J, Cui X (2020) Fate of sodium and chlorine during the co-hydrothermal carbonization of high-alkali coal and polyvinyl chloride. Fuel Process Technol 199:106277 